\title{
Juvenile rheumatoid arthritis with rice bodies: light and electron microscopic studies
}

\author{
C. ROSALES WYNNE-ROBERTS AND JAMES T. CASSIDY
}

From the Division of Rheumatology-Immunology, Department of Medicine, Southern Illinois University School of Medicine, Springfield, Illinois, and the Rackham Arthritis Research Unit, Department of Internal Medicine, University of Michigan Medical School, Ann Arbor, Michigan, USA

SUMMARY Rice bodies obtained from a young man with juvenile rheumatoid arthritis were found by light and electron microscopy to contain cells that appeared viable. The majority of these cells closely resembled type B synovial lining cells. Type A-like cells were also seen. The cells contained few mitochondria but often much lipid and glycogen, observations which suggested a dependence on anaerobic metabolic pathways in the avascular synovial fluid environment. Cells within the rice bodies lay in a matrix of collagen fibres, fibrin, and amorphous material. The source of the collagen appeared to be the cells themselves. The relatively normal appearance of the cells suggested that they were protected from many of the inflammatory stimuli present in rheumatoid synovia. This 'reversion' towards a normal appearance suggested that the stimuli inducing chronic rheumatoid inflammation might not originate in the synovial lining.

Rice bodies, so named because they resemble polished white rice, were extensively described almost a century ago by Riese (1895). In his classic study he reported the microscopic characteristics of rice bodies obtained from the synovial fluids of patients with tuberculous arthritis. There are no reports of the frequency of rice bodies in synovial fluids from patients with chronic synovitis or in association with specific diseases such as rheumatoid arthritis. In fact our clinical impression is that rice bodies are relatively uncommon. In 1965 Albrecht et al. (1965) described biochemical and ultrastructural details of rice bodies from adults with rheumatoid arthritis. The rice bodies from these cases were small and contained only cell remnants; thus, their description of cellular structure was necessarily limited. The present report describes the light and electron microscopic appearance of the cells and matrix of rice bodies obtained from a young man with juvenile rheumatoid arthritis.

\section{Case report}

The patient is a young white man who developed arthritis of the left knee at the age of 15 years in

Accepted for publication 17 April 1978

Correspondence to Dr James T. Cassidy, R4633 Kresge

Medical Research Building, University of Michigan Medical School, Ann Arbor, Michigan 48109, USA.
1973. Swelling of the left calf followed, and an arthrogram showed rupture of a popliteal cyst. Numerous rice bodies were removed at synovectomy, and the synovium was described as hyperaemic and inflamed. The knee improved during the next year. The left ankle became swollen in the autumn of 1974 and the right knee in early 1975 . The latter joint was aspirated at that time, and $50 \mathrm{ml}$ of yellow turbid fluid was removed. The white cell count was $49000 / \mathrm{mm}^{3}$ with $96 \%$ polymorphonuclear neutrophils. A few inclusion bodies were present. The mucin clot was poor. Cultures were negative. A consistent programme of aspirin was started at that time.

By June of 1975 the left knee had become massively swollen. A large effusion was aspirated and numerous rice bodies were evacuated as completely of as possible through a 16 gauge needle before injec- $N$ tion of intra-articular steroid. The fluid was nearly $\underset{\omega}{N}$ colourless but very turbid. The white cell count was $12500 / \mathrm{mm}^{3}$ with $74 \%$ polymorphonuclear neutrophils. The mucin clot was fair. No crystals were $\frac{0}{\Phi}$ seen. A few inclusion bodies were present. The rice $\stackrel{?}{\rightarrow}$ bodies were cut readily with a razor, a finding which suggested a low collagen content.

Symptomatic relief was only temporary and a few rice bodies were obtained intermittently from the $\mathbb{D}$ left knee. The right calf became swollen in the autumn of 1975 and a firm popliteal cyst enlarged 
behind the right knee. In October of 1976 moderate effusions of both knees, together with a small right popliteal cyst were still present. Full extension was preserved at both knees but flexion was limited to approximately $110^{\circ}$.

\section{LABORATORY DATA}

The Westergren erythrocyte sedimentation rate has varied between 40 and $53 \mathrm{~mm} / \mathrm{h}$. Tests for antinuclear antibodies and rheumatoid factors have been negative. The peripheral blood lymphocytes were negative for HLA B27 antigen. Ophthalmological examinations have given normal results. Radiographs of the left knee between 1974 and 1975 showed periosteal new bone formation along the medial and lateral femoral condyles and the posterior tibial metaphyseal area. Films have continued to show soft tissue swelling about both knees and the left ankle. A sub-Achilles bursitis with an erosion of the posterior tibial cortex was seen on the left in 1976. Frontal stereoscopic views of the sacroiliac joints have been negative.

\section{Materials and methods}

The rice bodies obtained at arthrocentesis were fixed immediately in $2 \%$ paraformaldehyde in 0.01 $\mathrm{M}$ phosphate buffer, pH $\mathbf{7 \cdot 2}$. The bodies were diced into 0.5 to $1.0 \mathrm{~mm}$ cubes. After 3 washes in cold $0.01 \mathrm{M}$ phosphate-saline buffer, the tissues were postfixed in Millonig's $1 \%$ osmium, $\mathrm{pH} 7 \cdot 2$, for $2 \mathrm{~h}$ at $4^{\circ} \mathrm{C}$ (Millonig, 1961). The specimens were dehydrated in a graded sequence of ethanols to $100 \%$ then infiltrated by and embedded in Spurr epoxy resin (Spurr, 1969).

Thick $1.0 \mu \mathrm{m}$ and ultrathin sections were cut on a Reichert ultramicrotome. The thick sections were stained with $1.5 \%$ aqueous toluidine blue 0 . The ultrathin sections were mounted on Formvar and carbon-coated copper grids and stained with a saturated solution of uranyl acetate in $50 \%$ ethanol and with Reynolds's lead citrate solution (Reynolds, 1963). The grids were examined in a JEOL 100B electron microscope at $60 \mathrm{kV}$.

\section{Results}

\section{LIGHT MICROSCOPY}

The rice bodies after aspiration appeared as a mass of loosely aggregated material (Fig. 1). The individual rice bodies varied from 0.2 to $1.5 \mathrm{~cm}$ in length and were oval to slightly irregular in shape. They were white to slightly yellow and were contained in blood tinged synovial fluid. The toluidine blue $\mathbf{O}$ thick sections showed cells scattered in a blotchy, purple-blue amorphous matrix (Fig. 2). Fibrils were
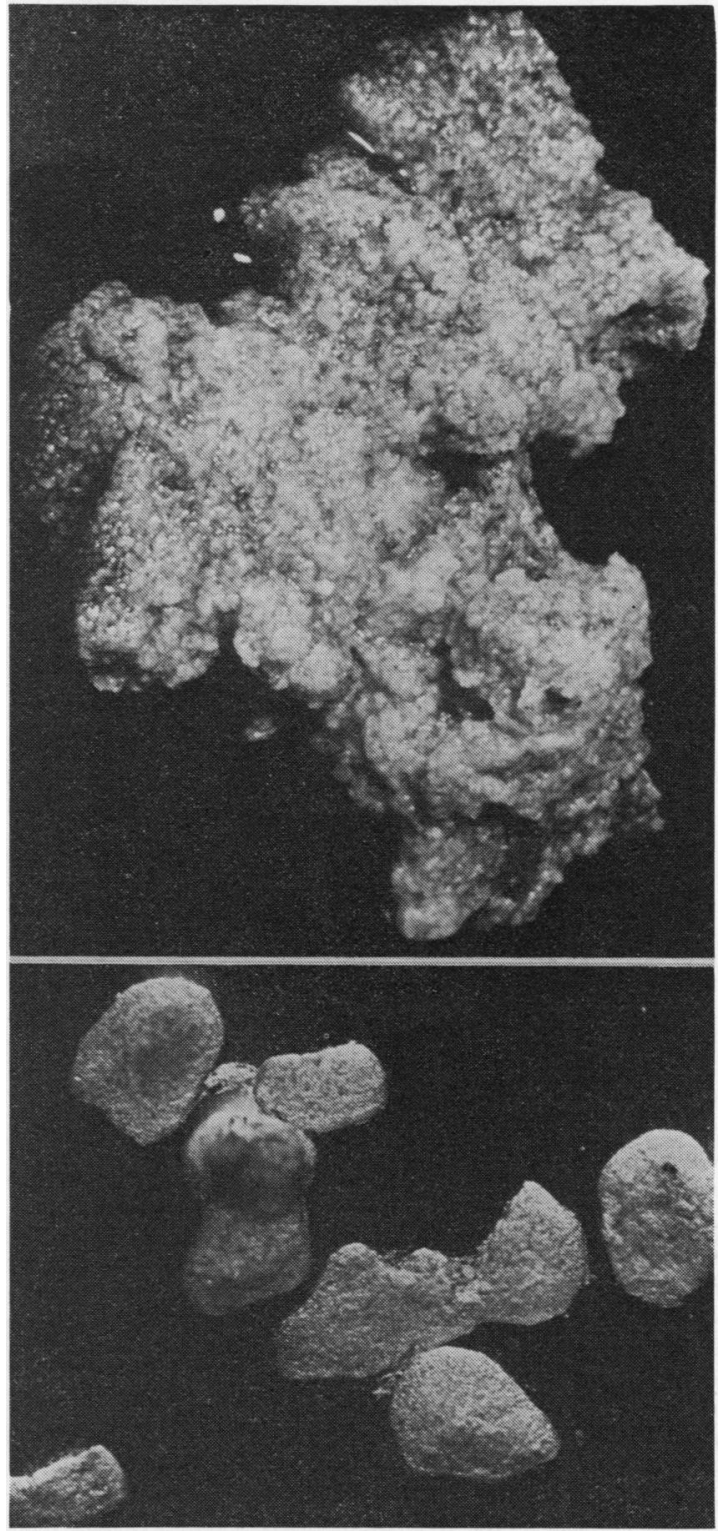

Fig. 1 Above: A mass of aggregated material containing rice bodies aspirated from a 17-year-old man with juvenile rheumatoid arthritis $(\times 4)$. Below: Individual rice bodies of sizes 0.3-0.6 mm. Some are oval and pebble-like ( $\times 14)$.

seen around the periphery. Cells of sizes 7 to $21 \mu \mathrm{m}$ appeared viable, and most were surrounded by pale blue or clear zones. Three types of cells were seen. Some resembled synovial lining cells and sometimes contained granules; some were spindle-shaped and 


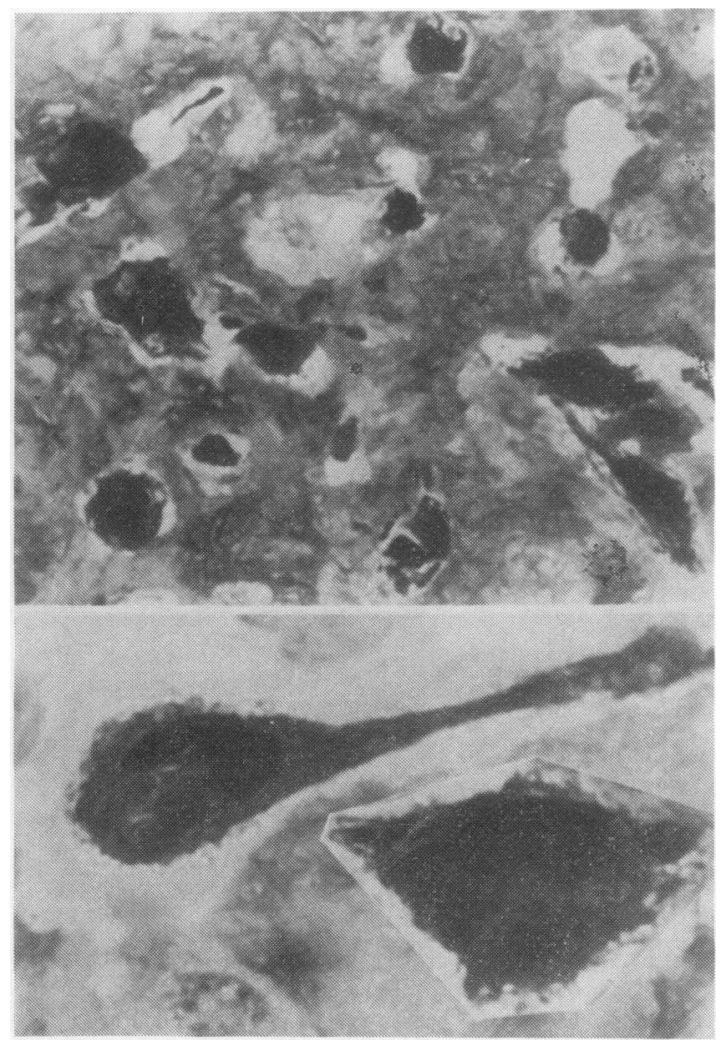

Fig. 2 Above: An overview of a portion of the interior of a rice body showing the mottled staining matrix. Cells of various shapes and sizes lie within relatively clear zones. Cell processes and filopodia can be seen in some instances. (1.5\% aqueous toluidine blue $0,1.0 \mu \mathrm{m}$ Spurr embedded thick section, $\times$ 1080). Below: Two cell types are shown. The upper elongated cell is fibroblast-like and shows metachromatic staining suggesting the presence of glycogen or mucopolysaccharides. Filopodia are seen at the cell surface. The cell itself lies in a relatively clear zone of rice body matrix. The lower cell contains dark granules and has marked filopodia formation ( $1.5 \%$ aqueous toluidine blue O, 1.0 um Spurr embedded thick section, $\times 3200)$.

oval cells containing pale blue vacuoles and areas of purple staining were present. That these latter cells might contain mucopolysaccharides or glycogen was suggested by their metachromatic staining. All cells had either long cell processes or short filopodia. Polymorphonuclear leucocytes, macrophages, lymphocytes, and plasma cells were not found within any rice bodies, nor were calcium salts observed.

\section{ELECTRON MICROSCOPY}

The predominant cell within the rice bodies was most like a type B synovial lining cell (Fig. 3)
(Barland et al., 1962). Some of these were spindle- $\frac{\bar{N}}{\omega}$ shaped and similar to fibrocytes of deeper areas of $\overrightarrow{\vec{F}}$ the synovium. All cells appeared viable and to be in $\stackrel{\oplus}{+}$ active protein synthesis as shown by well developed $\bar{C}$ rough endoplasmic reticulum. The lamellae of the $\underline{\underline{F}}$ endoplasmic reticulum were often dilated, and their $\frac{\bar{c}}{7}$ contents were homogeneous in appearance. No $\stackrel{\mathbb{Q}}{\Omega}$ intra-articular collagen fibril formation was noted. क Most cells contained glycogen and sometimes large $\vec{\circ}$ lipid drops (which appeared to correspond to the pale blue vacuoles of the toluidine blue stained $\vec{\omega}$ sections). The lipid was nonmembrane bound and often surrounded by the glycogen granules. Mitochondria were sparse, markedly fewer than usual, and $\dot{\omega}$ centrioles were occasionally seen. Dark staining lysosomal granules were present in moderate num- $\infty$ bers in some cells and were few in others. Dark 9 staining granules were also seen extracellularly close to cell surfaces and were often entwined in filo- T podia (Fig. 4). Some granules had the appearance of being phagocytosed; occasionally an intracellular granule was bound by a double membrane. Groups of free ribosomes were seen in the cytoplasm, and $\vec{\theta}$ microfilaments were easily observed. Microtubules cै were not noted. Interestingly, Golgi apparatus was rarely observed within any cells. Nuclei generally were slightly irregular in shape and contained 1 or 2 nucleoli. No particles suggestive of virus or mycoplasma were seen within any cells. Cell membrane activity was marked as shown by many slender filopodia and micropinocytotic vesicles (coated pits). Around most of the cells was a zone of collagen fibres, sometimes with fine whiskery material (Fig. 4, inset A). The collagen fibres were occasionally aligned in parallel with each other; however, most were short and without specific orientation. The periodicity of the collagen was $66 \mathrm{~nm}$. The immediate area around a few cells was almost devoid of any amorphous material or fibres. Away from the zones of collagen a mesh of amorphous material and fibrin (sometimes with a periodicity typical of coagulated fibrin) made up the mass of a rice body (Fig. 4, inset B). One effete polymorphonuclear neutrophil was seen by electron microscopy. The nucleus was homogeneous and the cytoplasm was partially $\tilde{N}$ destroyed.

\section{Discussion}

Rice body formation occurs in a small number of $\stackrel{\mathcal{D}}{\rightarrow}$ patients with adult rheumatoid arthritis, and in this 0 report we note this phenomenon in a young man with a persistent course of late-onset, oligoarthric juvenile rheumatoid arthritis. The more usual finding in rheumatoid synovial fluids is that of clumps of fibrin, a byproduct of inflammation 


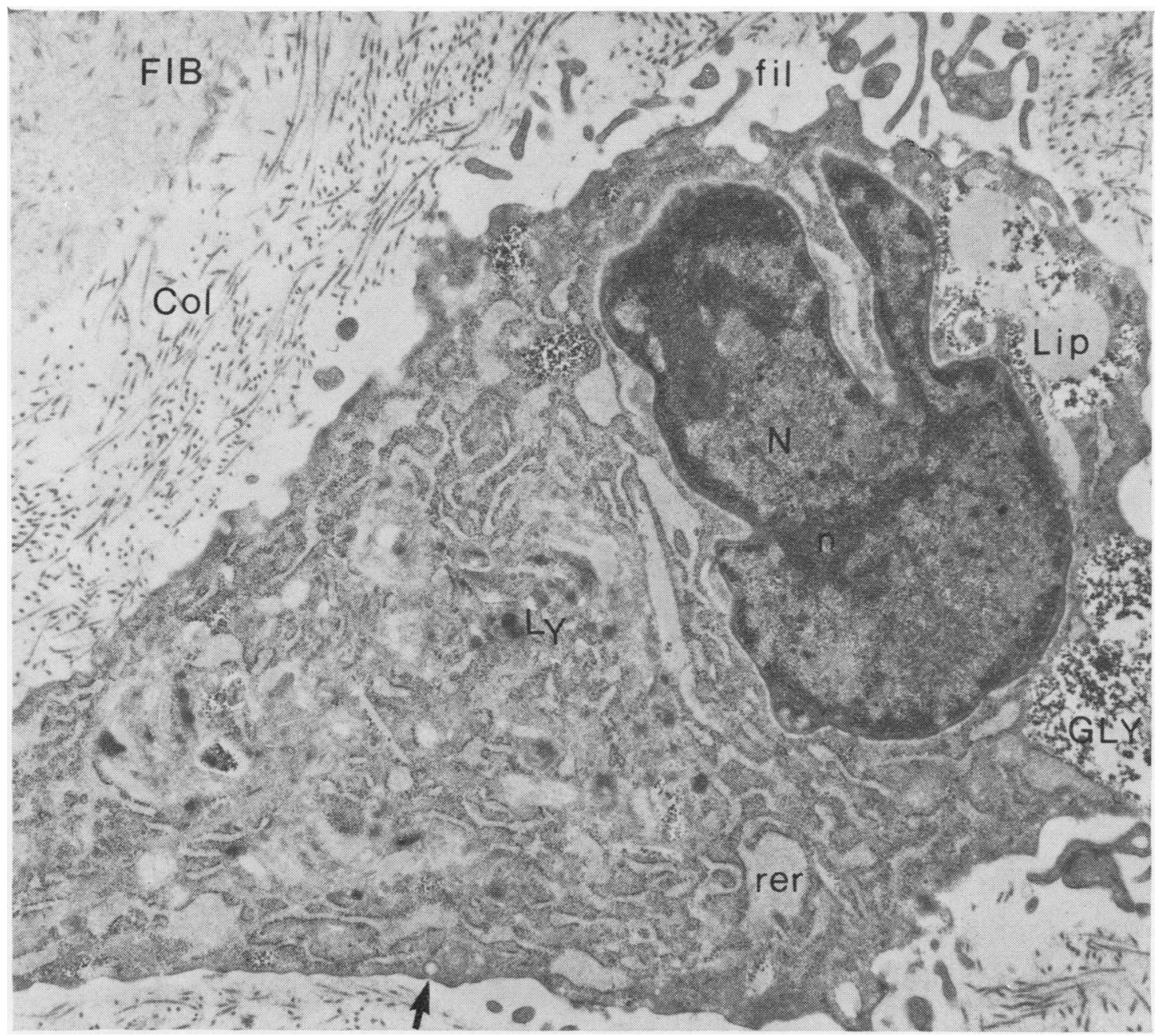

Fig. 3 Part of a 'synthetic' or B type appearing fibroblast containing very well developed rough endoplasmic reticulum lamellae (rer). No mitochondria can be identified in this view; however, nonmembrane bound lipid (Lip) and glycogen (GLY) can be seen. The pericellular area contains small collagen fibres (Col). Fibrin (FIB) is seen well away from the cell. Filopodia ( $f i l)$, lysosomes $(L y)$, nucleus $(N)$, nucleolar material $(n)$. The arrow points to a micropinocytotic vesicle (coated pit) (uranyl acetate, lead citrate, $\times 9600$ ).

(Cohen et al., 1975). The morphology of the cells within these rice bodies suggested their synovial origin, presumably from sloughing lining cells. The cytoplasmic appearance of the rice body cells was closer to that of normal B lining cells than A cells (Barland et al., 1962). This suggested that the environment, though porous to nutrients, was a protected one, that the cells could proceed primarily with collagen and hyaluronate synthesis, and that some of the intense stimuli to primary lysosome formation which are present in the inflamed rheumatoid synovial lining were excluded. The differences from normal lining cells which were seen in these cells suggested that local environmental factors within the rice bodies produced them. The lipid and glycogen observed and the relative paucity of mitochondria suggested the greater use of anaerobic pathways of energy utilisation in this avascular environment of synovial fluid. To some extent the cells' appearances were reminiscent of fibroblasts grown in tissue culture, especially cultures maintained for longer than 1 week without trypsinisation (Wynne-Roberts and Castor, 1972).

The explanation for the extracellular granules, 


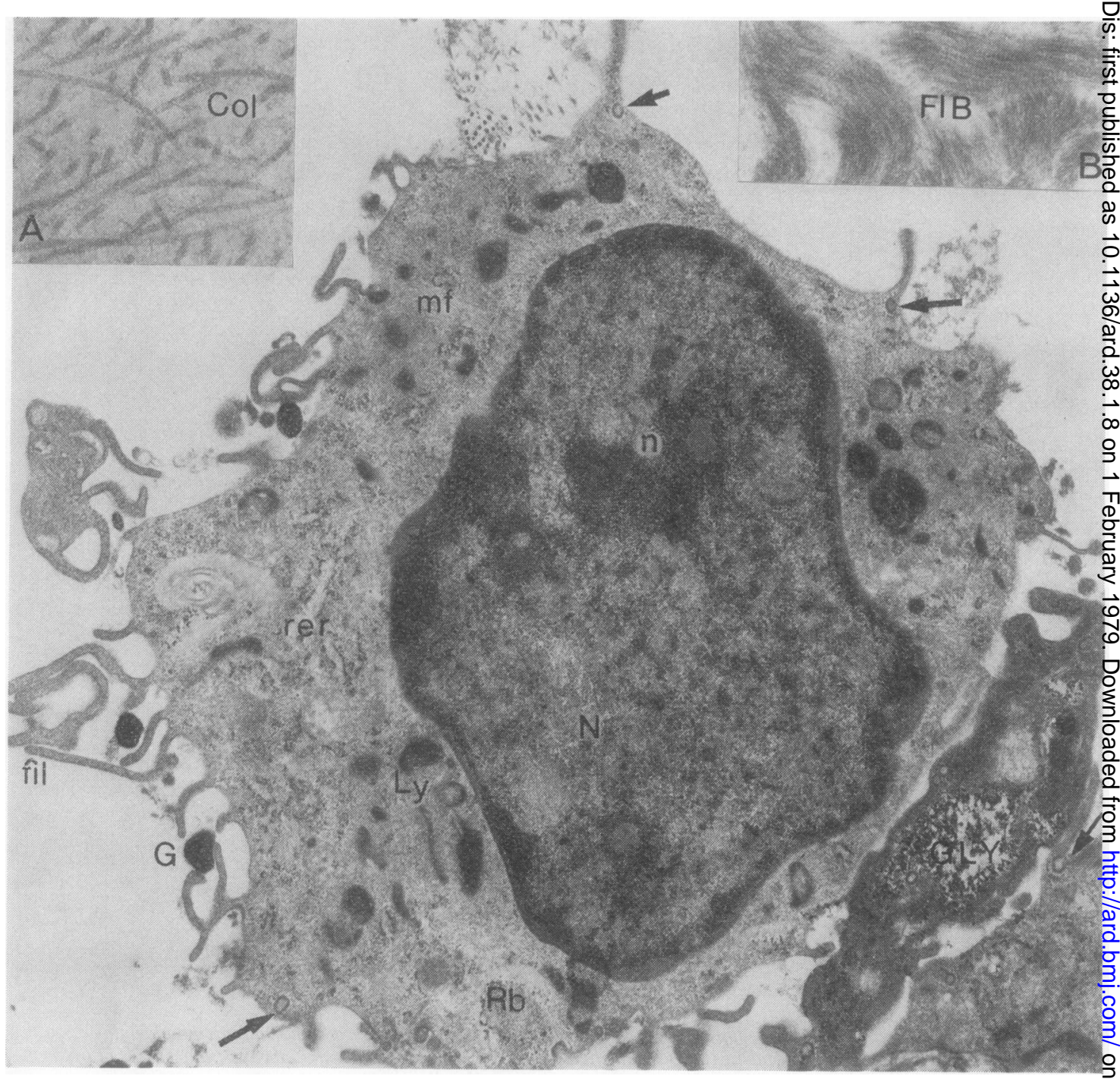

Fig. 4 A more A-like cell showing marked filopodia formation (fil). The extracellular granules $(G)$ may be in the process either of being extruded or of being ingested by the cell. The cell contains little rough endoplasmic reticulum (rer) and pleomorphic dark staining granules, some of which are most likely lysosomes $(L y)$, while others may be phagolysosomes or perhaps residual bodies. Free ribosomes $(R b)$ are scattered in the cytoplasm. Well marked micropinocytotic vesicles are arrowed. Nucleus $(N)$, nucleolus $(n)$, glycogen $(G L Y)$, microfilaments $(m f)$ (uranyl acetate and lead citrate, $\times 12000$ ). A: Small collagen fibres $(\mathrm{Col})$ show periodicity which measures $66 \mathrm{~nm}$ (uranyl acetate and lead citrate $\times 34000$ ). B: Fibres from a rice body matrix show the appearance and periodicity typical of coagulated fibrin $(F I B)$ (uranyl acetate and lead citrate, $\times 34000)$.

some apparently being phagocytosed, was not obvious. Their appearance was certainly similar to that of some intracellular lysosomes. Reasons for the pericellular clear zones might include an artefact of dehydration or that the cells secreted enzymes into their immediate vicinity, which destroyed fibrin. Possibly some of the extracellular granules might also play a role in fibrin destruction. Over $a+$ period of time the cells would then secrete collagen? and mucopolysaccharide matrix into the pericellularo area.

The rarity of inflammatory cells within these rices 
bodies is of profound interest. Their presence might be expected if the mechanism of formation of rice bodies consisted only of chance trapping of cells in fibrin in or on the synovial lining layer. The exclusion of these other cell types from rice bodies may be related to a variety of circumstances. Polymorphonuclear leucocytes are normally viable for about 3 days and are then either phagocytosed at the synovial surface by lining cells or die in the synovial fluid. The absence of lymphocytes and macrophages may be partially explained by their fewer numbers in rheumatoid synovial fluids despite their longer viability than neutrophils. It is possible that inflammatory cells avoid trapping in fibrin if they are more actively mobile than synovial lining cells.

It is likely that an individual rice body develops over weeks to months. Initially, a nidus of 1 or more lining cells is trapped in fibrin. This cell nidus is probably joined by other similar islands in the course of synovial fluid movement within the joint. The oval appearance of a rice body suggests that it has been subjected to movement, for example, rolling around within the joint in a manner similar to the polishing of stones on a sea shore or in a tumbler. This rolling motion would have to occur away from the weight or pressure bearing areas of the joint and presumably within the niches and folds of the synovial lining. The formation of a mucopolysaccharide matrix and the secretion of collagen by the entrapped cells would most likely contribute to the cohesiveness of the rice body.

From the available studies it appears as though there is a spectrum of histological structure and biochemical composition of rice bodies. In a recent publication Berg et al. (1977) examined rice bodies from 7 patients. They were found to consist of a fibrous matrix containing fibrin and variable but small amounts of collagen. A variety of viable cells were present: macrophages were most numerous, but fibrocytes, leucocytes, and red blood cells were also seen. Blood vessels occurred within 2 of the rice bodies indicating a recent attachment to the synovial membrane. The authors concluded from their study that rice bodies represent a nonspecific response to chronic inflammation.

In comparing our findings with those of Albrecht et al. (1965) we note that their rice bodies contained cellular fragments and lipid globules. Collagen was not present within the rice body matrix by morphological and chemical analyses. Protein-polysaccharide complexes, neuraminic acid, fibrin, and fibrin-like material were found. They concluded that rice bodies represented an end product of synovial inflammation, proliferation, and secondary degeneration.

The fact that the rice bodies we studied were larger (up to $1.5 \mathrm{~cm}$ long) and contained collagen and viable cells suggested that they had been present for weeks to months and that the collagen was indeed synthesised by the rice body cells. These cells appeared to be within a protected environment in the rice body and to have 'reverted' to a more nearly normal histological appearance. This observation suggests that the stimuli inducing chronic rheumatoid inflammation are brought to the synovial lining cells from elsewhere rather than that these stimuli occur primarily within the synovial lining and attract the invasive inflammatory response.

The technical assistance in preparation of tissue for electron microscopy by Ruth Blumershine, BS, of the Electron Microscopy Unit of the Southern Illinois University School of Medicine is gratefully acknowledged.

\section{References}

Albrecht, M., Marinetti, G. V., Jacox, R. F., and Vaughan, J. H. (1965). A biochemical and electron microscopy study of rice bodies from rheumatoid patients. Arthritis and Rheumatism, 8, 1053-1063.

Barland, P., Novikoff, A. B., and Hamerman, D. (1962). Electron microscopy of the human synovial membrane. Journal of Cell Biology, 14, 207-220.

Berg, E., Wainwright, R., Barton, B., Puchtler, H., and McDonald, T. (1977). On the nature of rheumatoid rice bodies. An immunologic, histochemical, and electron microscopy study. Arthritis and Rheumatism, 20, 13431349.

Cohen, A. S., Brandt, K. D., and Krey, P. R. (1975). Synovial fluid. Laboratory Diagnostic Procedures in the Rheumatic Diseases, 2nd edn., pp. 1-64. Edited by A. S. Cohen. Little, Brown: Boston.

Millonig, G. (1961). Advantages of a phosphate buffer for Os $\mathrm{O}_{4}$ solutions in fixation. Journal of Applied Physiology, 32, 1637.

Reynolds, E. S. (1963). The use of lead citrate at high pH as an electron opaque stain in electron microscopy. Journal of Cell Biology, 17, 208-212.

Riese, H. (1895). Die Reiskörperchen in tuberculös erkrankten Synovalsäcken. Deutsche Zeitschrift für Chirurgie, 42, 1-99.

Spurr, A. R. (1969). A low viscosity epoxy resin embedding medium for electron microscopy. Journal of Ultrastructure Research, 26, 31-43.

Wynne-Roberts, C. R., and Castor, C. W. (1972). Ultrastructural comparison of rheumatoid and nonrheumatoid synovial fibroblasts grown in tissue culture. Arthritis and Rheumatism, 15, 65-83. 